\title{
Building Inclusive Cities-Women's Safety and the Right to the City
}

Carolyn Whitzman, Crystal Legacy, Caroline Andrew, Fran Klodawsky, Margaret Shaw \& Kalpana Viswanath (Eds)

Abingdon, Routledge, 2013, 216 pp., ISBN 9780415628167

Building Inclusive Cities-Women's Safety and the Right to the City builds on and extends the body of literature relating to a rights-based approach to women's safety in the city and documents examples of emerging practice in this area. The book was inspired by, and evolved from, the proceedings of the 2010 Third International Conference on Women's Safety: Building Inclusive Cities, in New Delhi, India, and focuses on the right to an inclusive city.

An edited volume, Building Inclusive Cities is comprised of 12 chapters written by 16 contributors and is organised into three sections. A large part of the appeal of Building Inclusive Cities lies in the diversity of the contributing chapters and the differing perspectives of the authors.

Part 1 provides an overview of key global trends affecting women's lives, and goes on to explore and describe the challenges and opportunities that women face in regard to aspects such as housing security, mobility and accessing essential services. Fran Klodawsky (Carleton University, Canada), and Sara Ortiz Escalante (researcher and consultant) and Elizabeth Sweet (Temple University, USA), explore particular challenges and opportunities in relation to livelihoods, and migrant women's safety, respectively. The chapters illustrate the common contexts of poverty and social exclusion, and the importance of working towards reducing these to create cities that are socially inclusive.

A particular highlight of the book, in the reviewer's view, is Chapter 3, authored by Carolyn Whitzman (University of Melbourne, Australia). The chapter focuses on the challenges facing women in relation to safety and everyday mobility, and discusses transport-based interventions that aim to realise women's right to the city. The chapter includes a case study of Bogotá, where an integrated policy approach has promoted women's mobility and access to the city.

Part 2 of the book explores and discusses a range of interventions. Four action projects or programmes are used to examine ways in which the safety of women is compromised in a variety of settings. Creative and innovative ways in which women's safety and inclusivity in cities is being furthered through grass-roots and women's organisations which support community empowerment are then discussed and explored. Chapters written by Kalpana Viswanath (gender and urban safety scholar and advisor); Caroline Andrew (University of Ottawa, Canada) and Crystal Legacy (University of New South Wales, Australia); Barbara Holtmann (International Centre for Prevention of Crime and Women in Cities International); and Prabha Khosla (urban planner) and Suneeta Dhar (Jagori, a women's resource centre based in Delhi), explore a range of interventions and participatory techniques, including the Gender Inclusive Cities Programme, partnerships, collaboration towards a shared vision of inclusive cities, and the findings of research investigating women's access to basic infrastructure such as water and sanitation in Delhi. 
Part 3 of the book expands upon ways in which women's safety and building inclusive cities have been explored theoretically in the literature and discusses three concerns in the advancement of work in the area of safety of women and the right to the city. These concerns include gender mainstreaming and intersectionality in a chapter co-authored by Anita Lacey (University of Auckland, New Zealand), Rebecca Miller (Mahidol University, Thailand), Dory Reeves (University of Auckland) and Yardena Tankel (University of Auckland). The second theme explores opportunities presented by modern communications systems and the utilisation of these systems to promote women's safety in a chapter authored by Melanie Lambrick (artist and researcher, Canada). The third concern this part of the book discusses is the evaluation of programmes, and how to effectively evaluate knowledge relating to women's safety in a chapter written by Margaret Shaw (independent sociology and criminology consultant, Canada).

Building Inclusive Cities takes a cross-cultural viewpoint derived from research undertaken in a range of geographical locations. The book makes a valuable contribution to the established body of literature and research in the subject area, and would be of particular interest to researchers, scholars and those with an interest in discourses and empirical techniques relating to women's safety and inclusivity.

The editors have clearly made considerable effort to ensure that this edited book functions as a coherent and integrated whole, rather than as a series of discrete contributions. However, variations in the readability and written style of the various contributors inevitably remain. There are some notable gaps in the coverage of the book and these are acknowledged by the editors themselves. The inclusion of a chapter focusing on the implications of safety and inclusivity of women for urban planning practice would add value to any future editions of this volume, as would masculine perspectives and perspectives relating to governance and housing. The book would also be enriched with perspectives and contributions from a broader geographical spread of authors.

The black and white reproductions of figures and diagrams are at times difficult to read, in particular where a combination of small font and poor contrast result in the detail becoming difficult to discern in some diagrams. However, the book also contains full colour plates of these same diagrams in the middle of the book which are clearer and easier to read-though the font size remains small.

The editors consider that there "is no single vision of what a safe and inclusive city would look like, nor should there be" (p. 207). The editors note, however, that aspects such as access to livelihoods, housing, education and leisure activities would be features of the vision of safe cities. The pursuit of happiness, greater equality and a sense of empowerment regarding the shaping and use of public space, and an understanding of rights, more fully integrated into mainstream policies, would also be features. Building Inclusive Cities aims to provide ideas, case studies and inspiration promoting the realisation of visions of safe and inclusive cities.

Advancing the vision of safer and more inclusive cities for women and men, identifying tools and strategies to help move that vision closer to reality, and further specifying what it means to experience a right to the city-these are the motivators for the work. (p. 201) 
This reviewer considers that the authors have succeeded in achieving these goals.

Kate Mackness Environmental Planning Programme The University of Waikato, Hamilton, New Zealand katemack@waikato.ac.nz (C) 2013 Kate Mackness http://dx.doi.org/10.1080/08111146.2013.846247 